\title{
The utility of thiopurine methyltransferase enzyme testing in inflammatory bowel disease
}

\author{
Laura Chisick $M D^{1,2}$, Curtis Oleschuk PhD ${ }^{3}$, Charles N Bernstein $\mathrm{MD}^{1,2}$
}

\begin{abstract}
L Chisick, C Oleschuk, CN Bernstein. The utility of thiopurine methyltransferase enzyme testing in inflammatory bowel disease. Can J Gastroenterol 2013;27(1):39-43.
\end{abstract}

OBJECTIVE: To assess the levels of red blood cell thiopurine methyltransferase (TPMT) in subjects with inflammatory bowel disease (IBD) and to determine how these levels impacted thiopurine dosing and leukopenia over the first six months of therapy.

METHODS: A retrospective chart review was performed on all adult IBD patients ( $n=423,88.2 \%$ Caucasian) who had TPMT levels measured by 11 participating gastroenterologists in Manitoba between 2008 and 2010. In addition to descriptive data, white blood cell count, dose and reason for discontinuation were analyzed for the first six months of therapy. Patients receiving $\geq 2.0 \mathrm{mg} / \mathrm{kg}$ of azathioprine (AZA) or $\geq 1.0 \mathrm{mg} / \mathrm{kg}$ of 6 -mercapatopurine were considered to be 'substantially' dosed.

RESULTS: Of the 423 patients, $8.3 \%$ had intermediate levels and 93.4\% had normal levels of TPMT. Only one subject had a low level. A total of 216 patients had sufficient data to be included for full analysis. Patients with intermediate TPMT levels were generally started at lower doses of thiopurine than patients with normal TPMT levels (mean [ $\pm \mathrm{SD}] 1.0 \pm 0.6 \mathrm{mg} / \mathrm{kg}$ versus $1.8 \pm 0.5 \mathrm{mg} / \mathrm{kg}$ ). Of the subjects with normal TPMT levels, only $37.8 \%$ were dosed with $\geq 2.0 \mathrm{mg} / \mathrm{kg}$ of AZA. Each month, approximately $5 \%$ of subjects were leukopenic. These subjects received a mean overall AZA dose of $1.9 \pm 0.3 \mathrm{mg} / \mathrm{kg}$ and had a mean white blood cell count of $3.8 \pm 0.4 \times 10^{9} / \mathrm{L}$.

CONCLUSIONS: Normal TPMT levels did not prevent the development of leukopenia, although life-threatening leukopenia was rare. Physicians are not using TPMT levels to substantially dose thiopurines at the outset, which may limit the speed at which adequate doses are reached to facilitate remission.

Key Words: Crohn disease; Leukopenia; Ulcerative colitis; Thiopurines; Thiopurine methyltransferase

Tnflammatory bowel disease (IBD) is a chronic and relapsing immune1 mediated disease of the gastrointestinal tract, characterized by two distinct subtypes, ulcerative colitis (UC) and Crohn disease (CD). Our understanding of these IBD subtypes has evolved significantly in the past decade and, although the etiology and pathogenesis of IBD has not been fully elucidated, treatments have improved dramatically.

While many different therapies exist, the thiopurine drugs, namely azathioprine (AZA) and 6-mercaptopurine (6-MP), have shown benefits in the IBD population $(1,2)$. Initially introduced for the treatment of childhood leukemia, these drugs play a key role in the maintenance of remission $(1,3)$. They have also shown some benefit in patients with fistulizing disease and steroid-dependent illness $(4,5)$. However, treatment with these drugs comes with a price.

While the long-term threat of lymphoma in thiopurine users is of great concern, the most concerning - and potentially life-threatening immediate adverse event from thiopurine treatment has been myelosuppression. After oral ingestion, AZA is converted to 6-MP, which is

\section{L'utilité du test enzymatique de thiopurine méthyltransférase dans les maladies inflammatoires de l'intestin}

OBJECTIFS : Évaluer les taux de thiopurine méthyltransférase (TPMT) dans les globules rouges de sujets atteints d'une maladie inflammatoire de l'intestin (MII) et déterminer les effets de ces taux sur la dose de thiopurine et la leucopénie pendant les six premiers mois de traitement.

MÉTHODOLOGIE : Les chercheurs ont procédé à l'analyse des dossiers de tous les patients adultes ( $\mathrm{n}=423,88,2 \%$ de blancs) dont le taux de TPMT avait été mesuré au Manitoba par l'un des 11 gastroentérologues participants entre 2008 et 2010. En plus des données descriptives, ils ont analysé la numération des globules rouges, la dose et la raison de l'arrêt pendant les six premiers mois du traitement. Les patients qui recevaient au moins $2,0 \mathrm{mg} / \mathrm{kg}$ d'azathioprine (AZA) ou au moins $1,0 \mathrm{mg} / \mathrm{kg}$ de 6 -mercapatopurine étaient considérés comme recevant une dose «substantielle ».

RÉSULTATS : Sur les 423 patients, 8,3\% avaient des taux intermédiaires et 93,4\% des taux normaux de TPMT. Un seul sujet en présentait un taux faible. Au total, 216 patients disposaient de données suffisantes pour être inclus dans l'analyse complète. Les patients dont le taux de TPMT était intermédiaire commençaient généralement par des doses plus faibles de thiopurine que ceux dont le taux de TPMT était normal (moyenne $[ \pm \mathrm{SD}] 1,0 \pm 0,6 \mathrm{mg} / \mathrm{kg}$ par rapport à $1,8 \pm 0,5 \mathrm{mg} / \mathrm{kg}$ ). Sur les sujets dont le taux de TPMT était normal, seulement 37,8 \% recevaient une dose d'au moins $2,0 \mathrm{mg} / \mathrm{kg}$ d'AZA. Chaque mois, environ $5 \%$ des sujets étaient leucopéniques. Ils recevaient une dose moyenne globale de $1,9 \pm 0,3 \mathrm{mg} / \mathrm{kg}$ d'AZA et obtenaient une numération moyenne de $3,8 \pm 0,4 \times 10^{9} / \mathrm{L}$ de globules blancs.

CONCLUSIONS : Des taux de TPMT normaux ne prévenaient pas l'apparition de leucopénie, même si celles mettant en jeu le pronostic vital étaient rares. Les médecins n'utilisent pas les taux de TPMT pour administrer des doses substantielles de thiopurine dès le départ, ce qui peut limiter le délai avant de parvenir aux doses pertinentes pour favoriser la rémission.

then metabolized via three competing enzymatic pathways. Key enzymes within these pathways are xanthine oxidase, hypoxanthine guanine phosphoribosyltransferase (HPRT) and thiopurine methyltransferase (TPMT). Patients with little to no TPMT activity experience a loss of the inactivation pathways and there is preferential conversion of the thiopurines by HPRT to their active form, specifically, 6-thioguanine nucleotides. Using a standard dose in TPMTdeficient patients can lead to life-threatening myelosuppression.

TPMT genetic polymorphism was first described by Weinshilboum and Sladek in 1980 (6). Enzyme expression is inherited in an autosomal codominant fashion, with significant correlation between TPMT genotype and phenotype $(7,8)$. Within Manitoba, TPMT phenotype testing became widely available to physicians in 2008 . TPMT phenotyping, which is the measurement of red blood cell TPMT activity (as opposed to the genotyping of leukocyte DNA) avoids the complexity of defining the genetic polymorphisms within a patient complement. The genetic polymorphism in Caucasians has

${ }^{1}$ Department of Internal Medicine; ${ }^{2}$ University of Manitoba IBD Clinical and Research Centre; ${ }^{3}$ Department of Pediatrics and Child Health, University of

Manitoba, Winnipeg, Manitoba

Correspondence: Dr Charles N Bernstein, University of Manitoba, 804F-715 McDermot Avenue, Winnipeg, Manitoba R3E 3P4.

Telephone 204-789-3369, fax 204-789-3972, e-mail cbernst@cc.umanitoba.ca

Received for publication February 20, 2012. Accepted June 8, 2012 
TABLE 1

Descriptive subject characteristics

\begin{tabular}{lccc}
\hline & $\begin{array}{c}\text { Ulcerative } \\
\text { colitis }\end{array}$ & $\begin{array}{c}\text { Crohn } \\
\text { disease }\end{array}$ & Total \\
\hline Patients & $228(53.9)$ & $195(46.1)$ & 423 \\
$\begin{array}{l}\text { Age, years, median } \\
\text { (range) }\end{array}$ & $43(16-77)$ & $40(17-82)$ & $42(16-82)$ \\
Sex & & & \\
$\quad$ Female & $133(58.3)$ & $87(44.6)$ & $220(52)$ \\
Male & $95(41.7)$ & $108(55.4)$ & $203(48)$ \\
Ancestry & & & \\
Caucasian & $204(89.5)$ & $169(86.7)$ & $373(88.2)$ \\
Asian/Indian & $7(3.1)$ & $10(5.1)$ & $17(4.0)$ \\
First Nations & $7(3.1)$ & $4(2.1)$ & $11(2.6)$ \\
Metis & $1(0.4)$ & $3(1.5)$ & $4(0.95)$ \\
African American & $0(0)$ & $1(0.5)$ & $1(0.2)$ \\
Other & $5(2.2)$ & $5(2.6)$ & $10(2.4)$ \\
Not available & $4(1.8)$ & $3(1.5)$ & $7(1.6)$ \\
TPMT, nmol/gHb/h, & $60.0(1-136)$ & $61.0(22-135)$ & $59.5(1-136)$ \\
median (range) & & & \\
Patients within each TPMT (nmol/gHb/h) category & \\
Low (<10) & $1(0.4)$ & $0(0)$ & $1(0.2)$ \\
Intermediate (11-35) & $18(7.9)$ & $16(8.2)$ & $34(8.0)$ \\
Normal (>35) & $209(91.7)$ & $179(91.8)$ & $388(91.7)$ \\
\hline
\end{tabular}

Data presented as $n$ (\%) unless otherwise indicated. TPMT Thiopurine methyltransferase

been described and is the basis of clinically available TPMT genotype testing; however, there are less published data on enzyme levels in large populations.

With TPMT enzyme testing, the objective measure of red blood cell TPMT activity can be used to identify patients with little or no TPMT activity and to avoid thiopurines in their treatment. Alternatively, for a patient with normal enzyme activity, physicians can prescribe thiopurines relatively safely. Furthermore, dosing to recommended levels can be initiated with more confidence that sudden or profound leukopenia will not occur. However, because leukopenia remains a risk - even with normal TPMT levels - complete blood count levels must still be monitored. Patients with intermediate levels could be dosed with lower initial doses as an act of greater caution.

The aims of our retrospective cohort study were fourfold. First, we sought to identify the prevalence of low $(\leq 10 \mathrm{nmol} / \mathrm{g}$ hemoglobin $[\mathrm{Hb}] / \mathrm{h}$ ), intermediate ( $>11 \mathrm{nmol} / \mathrm{g} \mathrm{Hb} / \mathrm{h}$ but $\leq 35 \mathrm{nmol} / \mathrm{g} \mathrm{Hb} / \mathrm{h}$ ) and normal ( $>35 \mathrm{nmol} / \mathrm{g} \mathrm{Hb} / \mathrm{h}$ ). TPMT levels within a convenience sample of IBD patients. Second, we assessed to what extent 'substantial' doses ( $\geq 2.0 \mathrm{mg} / \mathrm{kg}$ AZA; $\geq 1.0 \mathrm{mg} / \mathrm{kg} 6-\mathrm{MP})$ were prescribed at drug initiation in patients with intermediate and normal TPMT levels. Third, we evaluated the prevalence and mean time to leukopenia (white blood cell [WBC] count $<4.5 \times 10^{9} / \mathrm{L}$ ) over the first six months of therapy. Finally, we identified adverse events and determined the number of subjects who subsequently discontinued thiopurine therapy.

\section{METHODS}

Subjects

In 2008, a database was initiated with the aim of collecting all TPMT levels checked in Manitoba, including all TPMT levels ordered by various physicians (including nongastroenterologists) across the province. TPMT levels from patients treated by 11 of 16 participating gastroenterologists practicing in both private practice and tertiary care settings were used for the purpose of the present study. A retrospective chart review was performed on each patient to determine the variables of interest, including IBD diagnosis (CD versus $\mathrm{UC}$ ), birthdate and age, sex, ethnicity, initial thiopurine (AZA or 6-MP) dose, weight, and initial and follow-up WBC counts. IBD diagnosis was established by each gastroenterologist according to clinical, endoscopic and histological findings, and documented in the chart. In cases for which ethnicity was not clearly described in the chart, physicians were asked to recall the information. Data were analyzed for the first six months of therapy (WBC count and dose) and any reasons for cessation of therapy during that time were also recorded. Reasons why patients may have had enzyme levels checked but were not initiated on therapy were also included. Leukopenia was defined as a WBC count $<4.5 \times 10^{9} / \mathrm{L}$ because this value is the conventional definition used by laboratories in Manitoba. Patients with WBC counts less than this would have their blood work automatically flagged by laboratories for physicians.

There were 452 subjects at least 18 years of age who had TPMT levels checked by the 11 gastroenterologists. Of these subjects, 29 were excluded because their diagnosis was not IBD. The remaining sample included 423 subjects (UC, $\mathrm{n}=228$; CD, $\mathrm{n}=195$ ) and was used to analyze prevalence data of low, intermediate and normal TPMT levels as well as baseline cohort characteristics such as age, sex, IBD subtype and ethnicity. While the optimal dose of thiopurines in IBD is truly unknown, generally, the target doses are considered to be $2.5 \mathrm{mg} / \mathrm{kg}$ for AZA and $1.0 \mathrm{mg} / \mathrm{kg}$ to $1.5 \mathrm{mg} / \mathrm{kg}$ for $6-\mathrm{MP}$. For the purposes of understanding whether initial TPMT levels were associated with 'substantial' doses, a dose $\geq 2.0 \mathrm{mg} / \mathrm{kg}$ for AZA and $\geq 1.0 \mathrm{mg} / \mathrm{kg}$ of 6 -MP were considered to be 'substantial'.

The study was approved by the Health Research Ethics Board of the University of Manitoba, Winnipeg, Manitoba.

\section{Analysis of TPMT activity}

Red blood cell TPMT activity was determined as described previously (9-11). Briefly, whole blood lysates from EDTA-treated blood were incubated with 6-thioguanine and the methyl donor S-adenosyl-Lmethionine to produce the methylated product 6-methylthioguanine. The reaction was stopped with perchloric acid and the 6-methylthioguanine was quantified by high-performance liquid chromatography fluorescence analysis (excitation $310 \mathrm{~nm}$, emission $390 \mathrm{~nm}$ ) using 4-aminoacetophenone as an internal standard. One of two technicians performed all assays.

\section{Statistical analysis}

For all quantitative variables, means and SDs were calculated. Medians and ranges are provided in all accompanying tables. For categorical variables, percentages were calculated.

\section{RESULTS}

Descriptive data are presented in Table 1 for the 423 subjects whose data were used to assess the distribution of TPMT levels. The mean $( \pm$ SD) age was $42 \pm 15.6$ years and $52 \%$ were female. The mean TPMT level was $59.9 \pm 16.5 \mathrm{nmol} / \mathrm{gHb} / \mathrm{h}$ (UC $58.3 \pm 16.1 \mathrm{nmol} / \mathrm{gHb} / \mathrm{h} ; \mathrm{CD}$ $61.9 \pm 16.9 \mathrm{nmol} / \mathrm{gHb} / \mathrm{h})$. The majority $(\mathrm{n}=373[88.2 \%])$ of subjects were Caucasian. Of the Caucasian subjects, one (0.3\%) had a low TPMT level, 31 (8.3\%) subjects had intermediate levels and 341 (93.4\%) subjects had normal levels. All subjects with low or intermediate TPMT levels were Caucasian with the exception of one Métis subject (mixed Caucasian and Aboriginal ancestry) and one First Nations subject (full Aboriginal ancestry).

Of the initial sample, 207 subjects were excluded from the remainder of the analysis. The most common reason for exclusion was that TPMT levels were checked in anticipation of the need for thiopurine therapy but therapy was not initiated (186 of 207 [89.9\%]). Twentyone subjects $(10.1 \%)$ had incomplete charts and were missing key data (such as baseline dose). Ultimately, 216 subjects had baseline thiopurine doses and usable data for at least a portion of the first six months of therapy. The mean age among the present cohort was $42 \pm 15.9$ years ( $52 \%$ female) in the UC group and $42 \pm 17.1$ years ( $45 \%$ female) in the CD group. Again, the majority (>90\%) of subjects were Caucasian in both CD and UC groups. These descriptive data were similar to the larger cohort described above.

Of these 216 subjects, 20 (9.3\%) subjects had intermediate TPMT levels and 196 (90.7\%) had normal TPMT levels. Initial AZA and 6-MP starting doses are shown in Table 2. Subjects with intermediate 
TABLE 2

Baseline doses (mg/kg) and white blood cell count (WBC) for patients with intermediate and normal thiopurine methyltransferase (TPMT) levels

\begin{tabular}{|c|c|c|c|}
\hline & $\begin{array}{c}\text { Ulcerative } \\
\text { colitis }\end{array}$ & $\begin{array}{l}\text { Crohn } \\
\text { disease }\end{array}$ & Total \\
\hline \multicolumn{4}{|c|}{ Subjects with intermediate TPMT levels $(n=20)$} \\
\hline Azathioprine $(n=19)$ & $1.1(0.3-2.2)$ & $0.9(0.6-2.0)$ & $1.1(0.3-2.2)$ \\
\hline 6-Mercaptopurine $(n=1)$ & None & $0.7(0.7)$ & $0.7(0.7)$ \\
\hline Baseline WBC, $\times 10^{9} / L^{*}$ & $9.9(6.7-17.6)$ & $6.4(3.8-7.5)$ & $7.5(3.8-17.6)$ \\
\hline \multicolumn{4}{|c|}{ Subjects with normal TPMT levels $(n=196)$} \\
\hline Azathioprine $(n=182)$ & $1.7(0.4-2.6)$ & $1.9(0.5-2.8)$ & $1.8(0.4-2.8)$ \\
\hline 6-Mercaptopurine $(n=14)$ & $1.1(0.8-1.3)$ & $1.1(0.5-2.8)$ & $1.1(0.5-2.8)$ \\
\hline Baseline WBC, $\times 10^{9} / \mathrm{L}^{\dagger}$ & $8.6(3.8-60.4)$ & $8.2(3.5-18.6)$ & $8.5(3.5-60.4)$ \\
\hline
\end{tabular}

Data presented as median (range). *Six patients with intermediate TPMTs did not have a baseline WBC; ${ }^{\dagger} 40$ patients with normal TPMT levels did not have baseline WBC count data

TPMT levels were generally started at lower doses than those with normal TPMT levels $(1.0 \pm 0.6 \mathrm{mg} / \mathrm{kg}$ versus $1.8 \pm 0.5 \mathrm{mg} / \mathrm{kg})$. Only two subjects $(10 \%)$ with intermediate TPMT levels were dosed substantially ( $\geq 2 \mathrm{mg} / \mathrm{kg} \mathrm{AZA;} \geq 1 \mathrm{mg} / \mathrm{kg} 6-\mathrm{MP}$ ) at baseline and they both completed six months of treatment without problems. The mean baseline WBC count was $8.6 \pm 3.8 \times 10^{9} / \mathrm{L}$ in the intermediate level group and $9.5 \pm 5.4 \times 10^{9} / \mathrm{L}$ in the normal level group. Seventy-four $(37.8 \%)$ subjects with normal TPMT levels were dosed substantially at baseline (36.2\% of UC subjects and $48.1 \%$ of CD subjects).

Although 216 subjects began treatment with thiopurines, 42 (19.4\%) did not complete even one month of treatment. The most common reason for cessation of treatment was development of 'flu-like' illness $(n=21[50.0 \%(10 \%$ of the overall cohort)]). This included fatigue, abdominal pain, nausea, vomiting, diarrhea and headache. Five patients $(11.9 \%$ [ $2.3 \%$ of the overall cohort]) discontinued treatment because of pancreatitis, of which two cases required hospitalization. One patient (2.3\% [0.5\% of overall cohort]) developed elevated liver enzyme levels and one patient developed a rash (2.3\% [0.5\% of overall cohort]). Hence, 28 subjects ( $13 \%$ of the overall cohort) who initiated thiopurines discontinued therapy within one month due to intolerance. Six subjects $(14.2 \%$ [2.8\% of overall cohort]) were hospitalized for various reasons potentially unrelated to therapy side effects including urosepsis, acute on chronic renal failure, fever of unknown origin, UC flare requiring surgery and other unclear reasons. Eight subjects (19.4\% [3.7\% of overall cohort]) discontinued therapy for other reasons, including a change in medications, nonadherence, flare of UC disease and lack of follow-up. In no case, regardless of TPMT level or AZA or 6-MP dosing, was a WBC count $<3 \times 10^{9} / \mathrm{L}$ recorded.

Of subjects with normal TPMT levels, 158 completed one month of therapy and 100 completed at least six months of therapy. Table 2 shows mean starting doses of AZA and 6-MP, and mean initial WBC counts. By three months, 28 subjects (18\%) had discontinued treatment or were lost to follow-up, with the most common reasons being

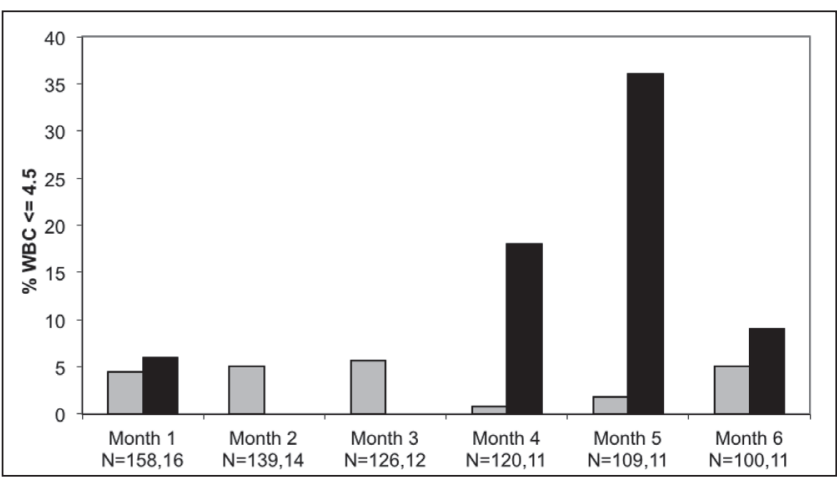

Figure 1) Percentage of leukopenic patients each month. Patients with normal thiopurine methyltransferase (TPMT) levels are illustrated in grey. Patients with intermediate TPMT levels are illustrated in black. The number of patients in each group is shown on the $x$-axis (number of patients in normal TPMT group, number of patients in intermediate TPMT group). WBC White blood cell count

lack of follow-up (seven subjects [25\% (7\% of entire cohort)]) and 'flu-like' illness (six subjects [21\% (6\% of entire cohort)]). On average, $5 \%$ of subjects were leukopenic each month, with a mean overall AZA dose of $1.9 \pm 0.3 \mathrm{mg} / \mathrm{kg}$ and a mean WBC of $3.8 \pm 0.4 \times 10^{9} / \mathrm{L}$ (Table 3, Figure 1). One subject taking 6-MP became leukopenic at one month; this same subject again became leukopenic at four and five months. Two other subjects taking 6-MP became leukopenic at three months, one of whom became leukopenic again at five months. These three subjects were taking doses of $6-\mathrm{MP}>1 \mathrm{mg} / \mathrm{kg}$. By six months, seven patients underwent dose reductions because of leukopenia.

Sixteen subjects with intermediate TPMT levels completed at least one month of therapy and 11 completed a full six months of therapy. All of these subjects were taking AZA. Of the five subjects who did not complete six months of therapy, four had stopped treatment by three months (lost to follow-up, hospitalization for pancytopenia (WBC $2.27 \times 10^{9} / \mathrm{L}, \mathrm{Hb} 93 \mathrm{~g} / \mathrm{L}$, platelets $78 \times 10^{9} / \mathrm{L}$ ), gastrointestinal symptoms and increased liver enzyme levels). By four months, two subjects had become leukopenic (mean WBC count $4.2 \pm 0.4 \times 10^{9} / \mathrm{L}$ ) and, by five months, two other subjects were leukopenic (mean WBC count $4.3 \pm 0.1 \times 10^{9} / \mathrm{L}$ ). By six months, five of 16 subjects with intermediate TPMT levels became leukopenic (Figure 1). Only one of five subjects who became leukopenic had to stop treatment because of leukopenia. However, one subject who became leukopenic in month 4 remained so to the end of the six-month follow-up period. The other patient who became leukopenic in month 4 remained leukopenic in month 5; however, with dosage adjustment, WBC levels increased by month 6. For these leukopenic subjects only, the mean AZA dose at month 4 was $2.4 \pm 0.2 \mathrm{mg} / \mathrm{kg}$, at month 5 was $1.7 \pm 0.9 \mathrm{mg} / \mathrm{kg}$ and, at month 6 , was $2.5 \mathrm{mg} / \mathrm{kg}$ (Table 3). None of the patients with intermediate TPMT levels underwent dose reductions because of leukopenia.

\section{TABLE 3}

Azathioprine (AZA) doses for subjects with leukopenia over the first six months of therapy, stratified according to thiopurine methyltransferase (TPMT) level

\begin{tabular}{|c|c|c|c|c|c|c|}
\hline & Month 1 & Month 2 & Month 3 & Month 4 & Month 5 & Month 6 \\
\hline \multicolumn{7}{|l|}{ Subjects with normal TPMT level } \\
\hline AZA dose, $\mathrm{mg} / \mathrm{kg}$ & $\begin{array}{c}1.5(1.0-2.6) \\
(n=9)\end{array}$ & $\begin{array}{c}2.0(1.0-2.4) \\
(n=7, \text { dose held } \\
\text { in } 3 \text { subjects })\end{array}$ & $\begin{array}{c}2.0(1.0-2.4) \\
(n=11, \text { dose held } \\
\text { in } 1 \text { subject })\end{array}$ & $\begin{array}{c}2.0(0.9-3.0) \\
(n=8, \text { dose not } \\
\text { assessed in } 1 \text { subject })\end{array}$ & $\begin{array}{c}2.0(1.0-2.6) \\
(n=7, \text { dose not } \\
\text { assessed in } 1 \text { subject })\end{array}$ & $\begin{array}{c}2.3(1.0-2.7) \\
(n=9, \text { dose not } \\
\text { assessed } n 1 \text { subject })\end{array}$ \\
\hline $\begin{array}{l}\text { Subjects with leukopenia taking } \\
\qquad A Z A \geq 2 \mathrm{mg} / \mathrm{kg}, \mathrm{n}\end{array}$ & 3 & 5 & 8 & 5 & 5 & 7 \\
\hline \multicolumn{7}{|c|}{ Subjects with intermediate TPMT level } \\
\hline AZA dose, $\mathrm{mg} / \mathrm{kg}$ & $0.5(n=1)$ & - & - & $2.4(2.2-2.5)(n=2)$ & $1.9(0.5-2.5)(n=4)$ & $2.5(n=1)$ \\
\hline
\end{tabular}

Data presented as median (range) unless otherwise indicated 


\section{DISCUSSION}

Thiopurines have been shown to be effective at maintaining remission in $\mathrm{CD}$ and, while there are less robust data for effectiveness, they are widely used in UC as well (1). Furthermore, recent data suggest that the combination of AZA and infliximab was more effective at maintaining remission out to one year than infliximab alone (12). Hence, these drugs will likely continue to have an important role in the management of IBD. Because of the potential for myelosuppression that is typically dose related, it has become recommended practice to estimate a patient's TPMT activity (either by phenotyping or genotyping) before initiating therapy $(13,14)$. It is our practice to use phenotyping for the measurement of TPMT enzyme levels. If levels are low, thiopurine therapy can be avoided because the risk for cytopenia would be too great. If the levels are intermediate, then dosing can be cautiously initiated and slowly increased while careful blood count monitoring is undertaken (monthly). Finally, if TPMT levels are normal, substantial dosing can be initiated. Because it takes approximately three weeks to reach homeostasis and, therefore, maximize the pharmacodynamic effect, more robust dosing at the outset can facilitate more rapid achievement of remission. With regard to this practice, our study highlights a number of key findings.

First, we report that in our majority Caucasian population, $92 \%$ had normal TPMT levels, $8 \%$ had intermediate levels and $<1 \%$ had low levels. These data are relatively consistent with the original data on TPMT genotype reported by Weinshilboum and Sladek (6), in which $11 \%$ of the population harboured heterozygous and $0.3 \%$ homozygous TPMT mutations, which correlate with intermediate and low TPMT phenotypic activity, respectively, and reports by others $(7,15)$ who additionally noted that for Caucasians, the genotype and enzyme levels correlated reasonably well $(15,16)$. Of our patient population, we found that among those with a normal enzyme level, only $37.8 \%$ were dosed with AZA $>2.0 \mathrm{mg} / \mathrm{kg}$ and $65.0 \%$ were dosed with AZA $>1.5 \mathrm{mg} / \mathrm{kg}$. Hence, clinicians were missing the opportunity to initiate substantial dosing to achieve the desired effect more quickly in these thiopurine users. We also found that in spite of having normal TPMT activity, each month, $5 \%$ of patients developed leukopenia during the course of therapy, and that the leukopenia could occur as long as six months postinitiation of thiopurine therapy. This highlights the importance of regular blood count monitoring regardless of the patient's TPMT activity. Additionally, because one subject had sufficiently abnormal liver enzyme levels that warranted therapy discontinuation, we believe this supports the need to check liver enzyme levels with initial blood testing, which we perform at one month.

Similar to other studies, we found that drug intolerance with thiopurines is an issue. In our study, we found that $28(13 \%)$ patients who received thiopurine therapy had discontinued the use of these drugs during the first month due to drug intolerance. This was somewhat independent of TPMT enzyme level because only four of these patients had intermediate TPMT levels. Similarly, in a meta-analysis of double-blinded randomized controlled trials, the incidence of adverse events sufficiently severe to cause withdrawal from thiopurine therapy was approximately $8.9 \%$ (17). In our study, there were only 111 of $216(51 \%)$ subjects who remained on therapy at six months. While there were several reasons for therapy discontinuation, our data are from a number of different gastroenterology practices and likely reflect a 'real world' experience.

There were several limitations to our study. First, there were missing data, including dosing and WBC, at baseline and for several months of follow-up for a number of study subjects. This made it difficult to accurately quantify the number of leukopenic patients as well as to reliably describe dosing practices in all subjects and, hence, we restricted our analysis to those for whom all data were available. This also serves as a reminder for clinicians to be vigilant with their patients about regular blood count monitoring and to know the starting point. Second, because the data reflect the experience of 11 of 16 Manitoba gastroenterologists, starting doses were far from uniform and, hence, the timing and/or incidence of leukopenia may have been underestimated if subjects were more uniformly dosed with more substantial doses. Even for subjects with normal TPMT enzyme levels, their AZA dosing was initiated at $<1.5 \mathrm{mg} / \mathrm{kg}$ approximately $35 \%$ of the time. Finally, the different prescribing practices of individual clinicians, regardless of patient weight or degree of illness, were evident throughout the present study. Physicians were not individually queried about their dosing patterns and, in one practice, patients were dosed at $50 \mathrm{mg}$ for the first week of therapy, followed by $100 \mathrm{mg}$ the next week and then $150 \mathrm{mg}$, up to the desired target dose. The rational for this approach may be explained by physician comfort level, the desire to avoid gastrointestinal side effects or the desire to avoid leukopenia in nonadherent patients who may not follow-through with complete blood counts. Finally, there were different clinical approaches to varying degrees of leukopenia. Some subjects had doses held when they became leukopenic whereas other subjects continued their drug but were simply monitored more closely. Because the present study was retrospective in nature, there was no protocol at the time directing when to stop therapy and when to continue.

\section{SUMMARY}

We corroborated the initial report of Weinshilboum and Sladek (6) with respect to the frequency of normal TPMT enzyme levels in a mostly Caucasian population. We also showed that $5 \%$ of thiopurine users with normal TPMT enzyme levels become leukopenic and, therefore, vigilance with monthly blood count monitoring must be maintained for at least six months. Finally, if thiopurines are to maintain a place in the therapeutic armamentarium of IBD patients, clinicians measuring TPMT levels should consider more substantial dosing initially to help facilitate more rapid pharmacological effects of the drug. Physicians must also be realistic with their patients when they are initiating thiopurine therapy. By six months, as many as one-half of subjects may no longer be using the drug either due to intolerance or lack of efficacy.

ACKNOWLEDGEMENTS: This study had no specific financial support. Dr Bernstein is supported, in part, by the Bingham Chair in Gastroenterology. He has consulted for Abbott Canada, Astra Zeneca Canada, Janssen Canada, Shire Canada, Vertex Pharmaceuticals and has received research grants from Abbott Canada and Prometheus Laboratories and an unrestricted educational grant from Aptalis. Drs Chisick and Oleschuk have no potential conflicts of interest to report. The authors thank Drs M Cantor, D Goldenberg, A Ilnyckyj, P Krongold, Y Lau, W Manishen, G Mathew, D Moffatt, L Targownik and H Singh for their help with this study.

\section{REFERENCES}

1. Khan KJ, Dubinsky MC, Ford AC, Ullman TA, Talley NJ, Moayyedi P. Efficacy of immunosuppresive therapy for inflammatory bowel disease: A systematic review and meta-analysis. Am J Gastroenterol 2011;106:630-42.

2. Prefontaine E, MacDonald J, Sutherland L. Azathiopurine or 6-mercaptopurine for induction of remission in Crohn's disease. Coch Databse Syst Rev 2009;(4):CD000545.

3. Dubinsky M. Azathioprine, 6-mercaptopurine in inflammatory bowel disease: Pharmacology, efficacy, and safety. Clin Gastroenterol Hepatol 2004;2:731-43.

4. Ardizzone S, Maconi G, Russo A, Imbesi V, Colombo E, Bianchi Porro G. Randomized controlled trial of azathioprine and 5 -aminosalicylic acid for treatment of steroid dependent ulcerative colitis. Gut 2006;55:47-53.

5. Sandborn W. A review of immune modifier therapy for inflammatory bowel disease: Azathioprine, 6-mercaptopurine, cyclosporine and methotrexate. Am J Gastroenterol 1996;91:423-33.

6. Weinshilboum R, Sladek S. Mercaptopurine pharmacogenetics: Monogenic inheritance of erthyrocyte thiopurine methyltransferase activity. Am J Hum Genet 1980;32:651-62. 
7. Yates CR, Krynetski EY, Loennechen T, et al. Molecular diagnosis of thiopurine S-methyltransferase deficiency: Genetic basis for azathioprine and mercaptopurine intolerance. Ann Int Med 1997;126:608-14

8. Rossi AM, Bianchi M, Guarnieri C, Barale R, Pacifici GM. Genotype-phenotype correlation for thiopurine S-methyltransferase in healthy Italian subjects. Eur J Clin Pharmacol 2001;57:51-4.

9. Ford L, Berg J. Determination of thiopurine S-methyltransferase activity in erythrocytes using 6-thioguanine as substrate and a non-extraction liquid chromatographic technique. J Chromatogr B Analyt Technol Biomed Life Sci 2003;798:111-5.

10. Ford LT, Cooper SC, Lewis MJ, Berg JD. Reference intervals for thiopurine S-methyltransferase activity in red blood cells using 6-thioguanine as substrate and rapid non-extraction liquid chromatography. Ann Clin Biochem 2004;41:303-8.

11. Ford L, Graham V, Berg J. Whole blood thiopurine S-methyltransferase activity with genotype concordance: A new, simplified phenotyping assay. Ann Clin Biochem 2006;43:354-60.

12. Colombel JF, Sandborn WJ, Reinisch W, et al; SONIC Study Group. Infliximab, azathioprine, or combination therapy for Crohn's disease. N Engl J Med 2010;362:1383-95.
13. Lichtenstein GR, Abreu MT, Cohen R, Tremaine W; American Gastroenterological Association. American Gastroenterological Association Institute technical review on corticosteroids, immunomodulators, and infliximab in inflammatory bowel disease. Gastroenterology 2006;130:935-9.

14. Gisbert J, Gomollon F. Thiopurine-induced myelotoxicity in patients with inflammatory bowel disease: A review. Am J Gastroenterol 2008;103:1783-800.

15. Chouchana L, et al. Screening of TPMT deficiency by phenotyping and genotyping: A retrospective study among 1,500 IBD patients in France. Gastroenterology 2011;140:S281-2.

16. Weinshilboum R. Thiopurine pharmacogenetics. Clinical and molecular studies of thiopurine methyltransferase. Drug Metab Disp 2001;29:601-5.

17. Pearson DC, May GR, Fick GH, Sutherland LR. Azathioprine and 6-mercaptopurine in Crohn's Disease. A meta-analysis. Ann Intern Med 1995;123:132-42.

18. Gisbert JP, Niño P, Rodrigo L, Cara C, Guijarro LG. Thiopurine methyltransferase (TPMT) activity and adverse effects of azathioprine in inflammatory bowel disease: Long term follow-up study of 394 patients. Am J Gastroenterol 2006;101:2769-76. 


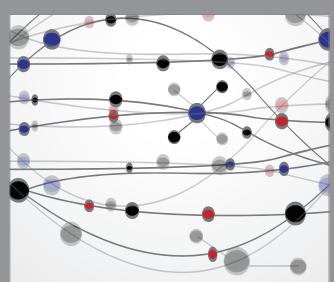

The Scientific World Journal
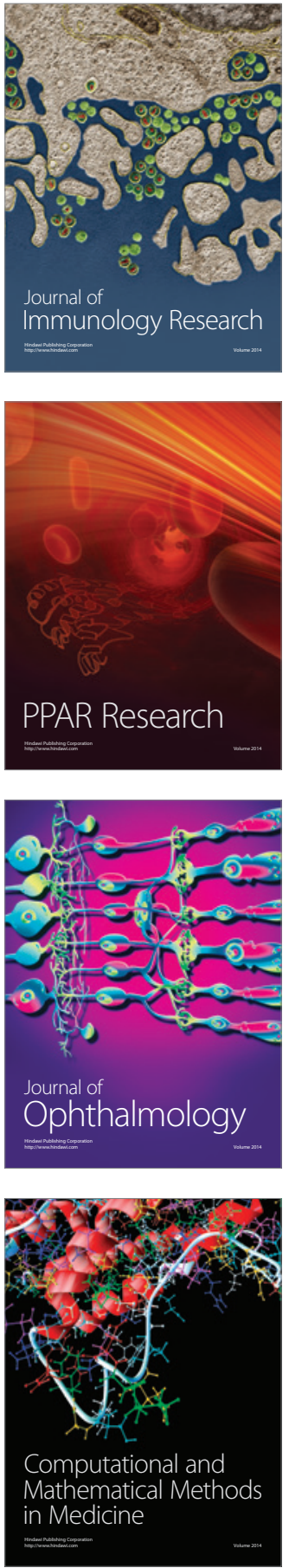

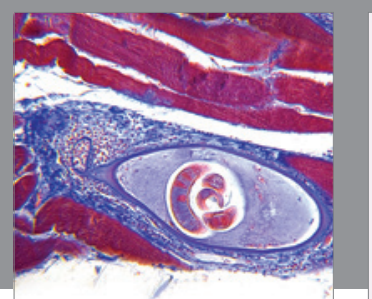

Gastroenterology Research and Practice

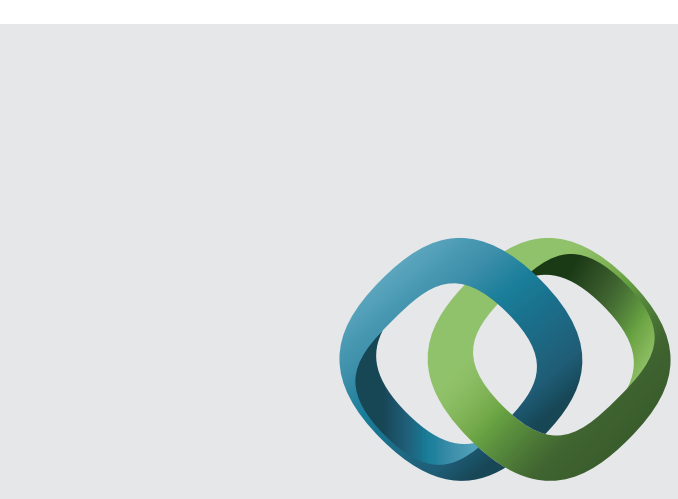

\section{Hindawi}

Submit your manuscripts at

http://www.hindawi.com
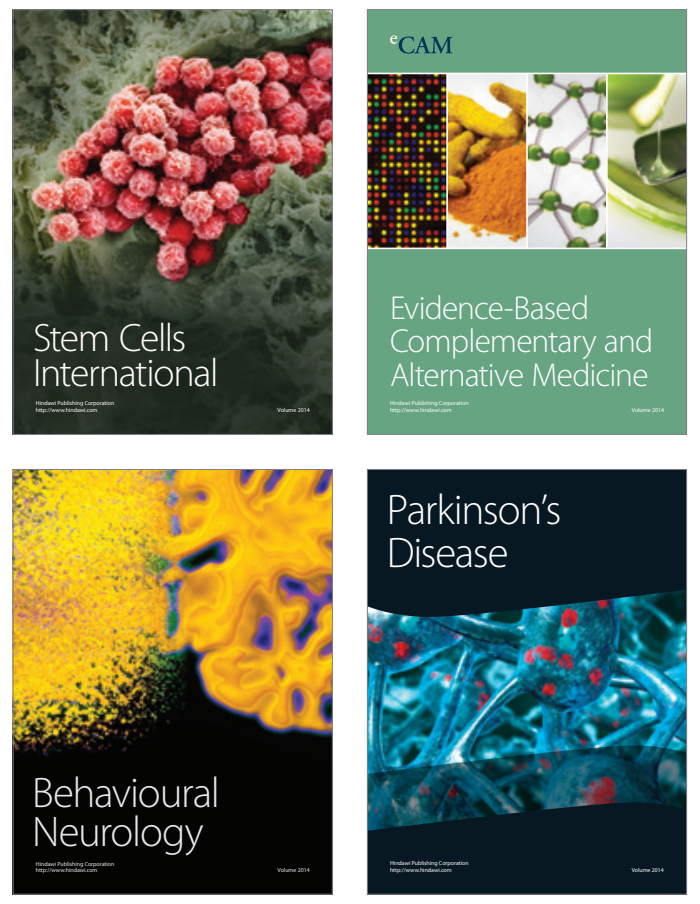
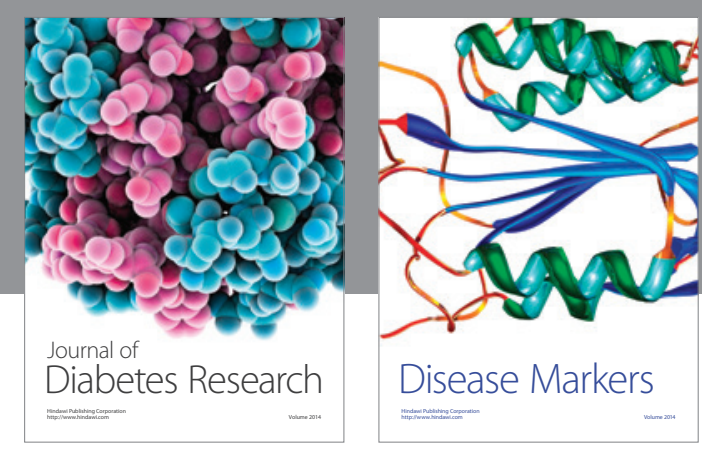

Disease Markers
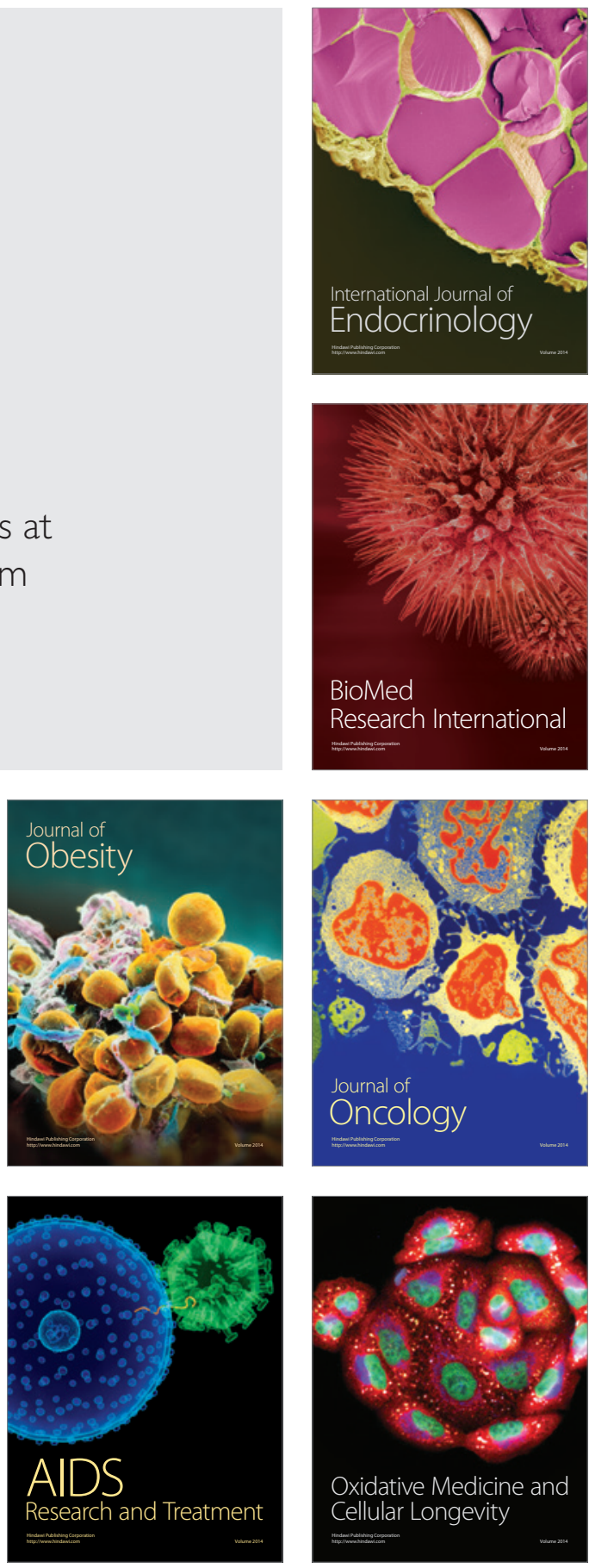